\title{
SUPER-HOMENS E PUBLICIDADE: reflexões sobre o tempo- mercadoria na produção de subjetividades performáticas
}

\section{SUPERMEN AND ADVERTISING: reflections about the time-commodity in production of performatic subjectivities}

\author{
Maria de Fátima SEVERIANO ${ }^{1}$ \\ Vanessa Ester Silva FARIAS ${ }^{2}$
}

Resumo: Em face do atual paradoxo entre a experiência de escassez de tempo e a expansão tecnológica midiática, no contexto da cultura do consumo, o presente artigo propõe uma reflexão acerca do papel da publicidade na veiculação de estilos de vida narcisistas modulados pelos ideais de performance, representados pela figura do "superhomem". Sob a inspiração dos teóricos da Escola de Frankfurt, tal fenômeno é analisado em peças publicitárias que fazem apelo à aceleração do ritmo de vida dos indivíduos, via objetos tecnológicos, considerando as repercussões psicossociais e as novas formas de controle.

Palavras-chave: Super-homens; Performance; Narcisismo; Tempo; Publicidade.

Abstract:In light of the current paradox between the scarcity of time experience and the media technological expansion, in the context of the consumption culture, this paper proposes a reflection about the role of advertising in propagating narcissistic lifestyles modulated by the ideals of performance, represented by figure of the "superman". Under the inspiration of the School of Frankfurt's theoreticians, this phenomenon is analyzed in advertisements that appeal to accelerating the pace of life of individuals, via technological objects, considering the psychosocial repercussion and new forms of control.

Keywords: Supermen; Performance; Narcissism; Time; Advertising.

\footnotetext{
${ }^{1}$ Psicóloga, graduada pela Universidade Federal do Ceará (1982), com doutorado em Ciências Sociais Aplicadas à Educação pela Universidade Estadual de Campinas - UNICAMP(1999) e com doutorado sanduíche no Depto. de Psicologia Social da Facultad de Ciencias Politicas y Sociologia da Universidad Complutense de Madrid. É Professora Associada III da Universidade Federal do Ceará no Departamento de Psicologia e Programa de Pós-Graduação desta Instituição. É autora do livro "Narcisismo e Publicidade: uma análise dos ideais do consumo na contemporaneidade", editado por AnnaBlume (SP) e Siglo XXI (Espanha/Argentina) e do livro "Consumo, Narcisismo e Identidades Contemporâneas" EdUERJ (RJ). Realizou Pós-Doutorado no Programa de Pós-Graduação em Psicologia Social da UERJ (2012). Email: fatimasev@terra.com.br

${ }^{2}$ Bacharel em Comunicação Social, habilitação em Publicidade e Propaganda pela Universidade Federal do Ceará (2012) com distinção Magna Cum Laude. Atualmente, é mestranda em Psicologia Social, linha de pesquisa Cultura e Subjetividades, pela Universidade Federal do Ceará. Possui interesse por temáticas relacionadas a: Cultura do Consumo, Temporalidades contemporâneas, Novas Tecnologias, Publicidade, Mídia, Culto da Performance e Teoria Crítica na contemporaneidade. E-mail: ester.farias08@gmail.com
} 


\section{Introdução}

De onde vêm os poderes dos super-heróis? O personagem de Jerry Siegel e Joe Shuter (1938), Superman, só é "super" porque a radiação de nosso Sol amarelo é diferente da radiação do Sol de seu planeta: Krypton. Ao passo que Tony Stark (criado por Stan Lee em 1963), o Homem de Ferro, seria apenas um homem rico, sem poderes fantásticos, não fossem as próteses tecnocientíficas que ele mesmo implantou em si, a começar por seu coração. Tony Stark é um gênio de alta performance, montado para ser super-herói. Há quem diga que essa é a real beleza não apenas de sua história, mas também da história de Bruce Wayne, o Batman (criação de Bob Cane e Bill Finger, 1939). Pois eles são homens “comuns", limitados, oriundos do mesmo planeta que nós; mas com bravura e uma não pequena ajuda de seus aparatos tecnológicos, são capazes de quase tudo.

Difícil não comparar essa fonte de poderes tecnocientíficos com o que vivemos hoje. Um tempo em que a expansão das novas tecnologias, sob os efeitos da ciência, da informática e da cibernética, alcançou níveis exponenciais de crescimento, possibilitando ao homem a realização de tarefas de forma simultânea e sem fronteiras. Aqui, no mundo real, tal como na ficção, o homem parece ter se tornado um "Deus de prótese", em que as limitações são ignoradas e a ideia de fazer "quase" tudo prevalece.

Ante as múltiplas benesses "ofertadas" pela atual sociedade de consumo, a atual indústria da produção de bens eletrônicos e midiáticos inundou o planeta com gadgets equipamentos cada vez mais miniaturizados, leves e práticos -, cuja portabilidade e interação com o corpo tornam o homem um receptáculo, sem mediações, das mais distintas demandas informatizadas. Neste sentido, o termo prótese (do grego prosthenos) designa não apenas um instrumento manipulável à serviço do corpo, mas como nos alertou Sodré (2006), assume a forma de uma "extensão especular ou espectral que se habita, como um novo mundo, com nova ambiência, código próprio e sugestões de conduta" (p.21).

Se não vejamos: aos múltiplos produtos que nos cercam em nosso dia-a-dia (celulares, notebooks, netbooks, pendrives, iPods, iPads, iPhones, câmeras 
miniaturizadas, dentre outros) e que se instalam no limite da fusão com o humano são atribuídos verdadeiros "poderes", inclusive de romper as barreiras do tempo e do espaço, tanto no interesse público, quanto privado. A tendência atual é a de vermos, seja no trabalho, seja nos lares, corpos "chipados" ou plugados às suas próteses eletrônicas que recebem fluxos informacionais de todas as partes do planeta; o que lhes confere poderes, antes inimagináveis. Assim, o corpo passa a ser o destino comum de informações, mensagens, imagens e produtos culturais de toda a sorte, tornando-se um veículo tecnológico excitável, sempre em estado de prontidão e potencialmente apto a realizar qualquer tarefa.

É nesse contexto de velocidade e hiperexcitabilidade do corpo, em meio aos ininterruptos fluxos de informação em altíssima velocidade, que utilizamos o termo "super-homens", o qual designa indivíduos performáticos, que mantêm uma constante aceleração em seus ritmos de vida, através de objetos e serviços tecnocientíficos, sempre em busca de upgrades em si mesmos, em estado de prontidão e de hiperatenção constantes.

Por outro lado, apesar de todas as próteses tecnológicas, o super-homem está sempre em busca de "mais tempo". Trata-se do fenômeno que Rosa (2010) denomina de famine temporelle (fome temporal), a qual, paradoxalmente, cresce à medida que se produzem e se disseminam mais e mais aparatos tecnológicos, constantemente veiculados pela mídia publicitária como a solução para todos os problemas. Assim, como antídoto à constante falta de tempo, o "super-homem" consome cada vez mais artefatos tecnológicos, os quais, por sua vez, instalam sempre mais demandas, concernentes à lógica concorrencial do sistema capitalista financeiro. Isto significa ter de fazer sempre mais coisas em menos tempo, resultando muitas vezes em um esgotamento do ser e em níveis de depressão e burn-out, jamais vistos. Quanto ao tempo, este se torna um dos bens mais raros e caros.

A Publicidade, como instância psicopedagógica de grande relevância para a constituição das subjetividades humanas contemporâneas, exerce um papel privilegiado no incremento desse processo. Através da veiculação de estilos de vida modulados pelos ideais de performance e empreendedorismo ela cultiva um terreno fértil para a produção de supostos super-homens. 
Isto porque a mídia publicitária aborda atualmente o "consumo" não apenas como uma mera expressão de troca mercantil, mas principalmente como um sistema complexo de comunicação e de poder; como uma linguagem, permeada por valores e ideologias, em que se ordenam signos sociais e subjetivos, capazes de promover a integração/exclusão de grupos, assim como o reconhecimento/rejeição de indivíduos. Regida pela lógica racional e econômica do mercado, se vale predominantemente da lógica do desejo para vender seus produtos, divulgando frequentemente um "estilo de vida acelerado", como perfil ideal.

Ora, nossa inquietude reside, justamente, nesse culto à aceleração, mediado pela mídia e pelas novas tecnologias e suas consequências para a subjetividade humana. Historicamente, apesar dos ideais iluministas de progresso ter encerrado um otimismo quanto ao futuro da humanidade, em face dos avanços da ciência e da técnica no domínio da natureza, os anseios por bem estar subjetivo, liberação do trabalho/labuta, realização existencial e felicidade não se concretizaram. Nem a automatização das máquinas, nem as telecomunicações, tampouco o advento das novas tecnologias foram capazes de tornar o tempo abundante. Ao contrário: o culto à velocidade se exacerba e se renova constantemente, via objetos tecnológicos de consumo. A tolerância pela espera é cada vez mais reduzida e a busca por acelerar todos os processos, serviços e até mesmo as relações interpessoais se expressa cotidianamente.

Considerando-se que as facilidades auferidas pelos recursos tecnológicos deveriam dar subsídios para a expansão do tempo livre, deparamo-nos com um dos grandes paradoxos da nossa história contemporânea: a experiência de crescente escassez de tempo, ao lado de uma incessante inovação e expansão, sem precedentes, das novas tecnologias informatizadas e midiáticas, no seio de uma sociedade de consumo. Como afirma Giannetti (2002, p.166): "Há um descolamento terrível entre as conquistas objetivas da tecnologia e a nossa experiência subjetiva do tempo. A sensação é a de que quanto mais economizamos tempo, mais carecemos dele - é a mendicância na opulência”.

Diante do exposto, nossa hipótese é a de que essa tentativa de adquirir poderes extra humanos é, em grande medida, uma resposta do homem para fazer frente ao referido paradoxo. Incitado constantemente pelas produções publicitárias, que vendem o 
tempo como uma mercadoria agregada aos produtos tecnocientíficos, parece ocorrer uma identificação idealizada com os personagens midiáticos, na medida em que estes fornecem receitas que "orientam" a como "vencer", em meio a escassez do tempo e a aceleração do viver. Para fazer frente a tantas demandas, há que ser um "super-homem".

As reflexões que se seguem possuem uma clara inspiração teórico-metodológica na Teoria Crítica da Escola de Frankfurt (Adorno, Horkheimer e Marcuse), aqui considerados enquanto os teóricos da suspeita. A partir de uma Crítica da Cultura, eles foram os pioneiros a denunciar as novas formas de dominação da sociedade industrial moderna, expressa especialmente no conceito de Indústria Cultural, na qual ocorreria uma dissipação das fronteiras entre a vida cultural e a produção econômica, com exclusivos fins mercadológicos. A compreensão dessa forma de poder evidenciou a ocorrência de um duplo deslocamento nas formas de controle social: do econômico para o cultural, assim como das formas explícitas e concretas para as imperceptíveis e simbólicas. Concebida como "a integração deliberada, a partir do alto, de seus consumidores" (ADORNO, 1986, p.92), o conceito de "Indústria Cultural" tem por mérito esclarecer muitos fenômenos vinculados ao ordenamento e modelação dos sonhos e desejos dos consumidores, a partir do mecanismo de reprodução ampliada das próprias necessidades e desejos dos indivíduos.

Interessa ainda ressaltar que para Marcuse (1982) a técnica não pode ser concebida de forma neutra, na medida em que ela sempre encarna um Projekt. Na técnica são projetados os interesses dominantes da sociedade e suas intenções com relação aos homens e às coisas: "A tecnologia serve para instituir formas novas, mais eficazes e mais agradáveis de controle social e coesão social” (p. 19).

Vejamos, portanto, qual o atual papel da indústria cultural, especialmente em sua forma publicitária, na produção do super-homem contemporâneo, em tempos acelerados.

\section{Super-homens e aceleração temporal}

A conhecida terminologia "super-homem", empregada nessa pesquisa, tem sido utilizada em diferentes sentidos ao longo dos anos. Algumas abordagens, mesmo que utilizando termos parecidos ou semelhantes, corroboram com a nossa concepção de 
indivíduo. A exemplo, temos o caso do "homem-jato", citado por Roland Barthes (1993), o qual:

parece não conhecer nem aventura nem destino; apenas uma condição e mesmo essa condição é, à primeira vista, menos humana que antropológica; miticamente o homem-jato define-se menos pela sua coragem, do que pelo seu peso, sua dieta e seus hábitos (temperança, frugalidade, continência). (p.63)

Essa definiçãa em especial vai ao encontro do que denominamos de "superhomem" por se tratar de um indivíduo "sem destino" e menos humano que antropológico. Porém, além disso, Barthes (1993) ainda endossa sua linguagem atribuindo o poder do homem-jato a uma "semidivindade" cujo pagamento é por meio da "moeda da "felicidade humana" (p.63). Ou seja, é possível que o homem tenha trocado sua simplicidade, liberdade, tempo livre e, enfim, sua felicidade pela busca incessante por "poderes", ou melhor, "superpoderes".

Em sua obra "O Culto da Performance", não por acaso, Ehrenberg (2010) retoma a ideia de heroísmo, para expressar uma tendência na modernidade: "para Baudelaire, todos estão forçados a ter de realizar uma proeza que os fazem grandes e pela qual são heróis da vida moderna" (EHRENBERG, 2010, p.12). O que implica em uma compensação feita pelos homens para salvarem a si mesmos: "Quando a salvação coletiva, que é a transformação política da sociedade, está em crise, a verborreia de challenges, desafios, performances, de dinamismo e outras atitudes conquistadoras constitui um conjunto de disciplinas de salvação pessoal” (EHRENBERG, 2010, p.13). Isto é, os heróis da contemporaneidade, diferente de muitos personagens mitológicos ou líderes do passado, não se caracterizam por sua coragem e bravura, nem por suas limitações que tornavam a vitória ainda mais glamorosa; muito menos por sua missão de salvação coletiva ou de estabelecer a "boa sociedade” (BAUMAN, 2001, p.76).

No lugar das altruístas características dos heróis do passado, os "super-homens" contemporâneos visam predominantemente a obtenção da própria salvação pessoal, num retorno a si mesmos. Ganham notoriedade mais pela busca por se igualarem ao ritmo das máquinas e, no máximo, se expõem como "conselheiros" sem quaisquer comprometimentos ou responsabilidades com as consequências de suas "lições". Eles 
provavelmente não morreriam por uma causa coletiva, mas cedem pouco a pouco o tempo de suas vidas para encontrar a própria felicidade.

É imprescindível frisar aqui que o termo "super-homens" evoca, em si, os "superpoderes" que emanam de produtos, especificamente, aqueles de natureza tecnocientífica, uma vez que aqueles dependem fundamentalmente destes para exercer seus poderes. Atributos tais como potência, velocidade, prontidão e reconhecimento social e afetivo são imputados aos produtos, como se emanassem naturalmente do próprio objeto - numa expressão contemporânea do fetichismo da mercadoria. A isto denominamos de o duplo fetichismo (SEVERIANO, 2007), em que estão alienadas na mercadoria não apenas as relações sociais de produção (MARX, 1984), mas a própria subjetividade humana, na medida em que atualmente são os próprios objetos que fornecem significados ao homem.

Trata-se do que Baudrillard (1976) denominou da lógica do valor sígnico da mercadoria, em que o objeto é orientado não pelo seu valor de uso, mas por um sistema distintivo de imagens de marca, ditado pela moda, que tem por função atribuir significados ao indivíduo, de acordo com os atributos subjetivos e de prestígio social agregados nos objetos. Neste caso, o objeto de consumo deixa de ser a solução para um problema prático para ser concebido em seus aspectos subjetivos, passando a ser a "solução de um conflito social ou psicológico" (BAUDRILLARD, 1993). O que significa dizer que os apelos se dirigem não às necessidades objetivas do homem, mas ao consumidor em seus aspectos desejantes; obturando carências e faltas de ordem subjetiva e ideal.

Os "super-homens" são a ideia-síntese de uma tendência social, crescentemente presente em nosso cotidiano. Resultado de um mundo que se acelerou triplamente: 1. L'accélération technique - aceleração técnica, que abrange o âmbito dos transportes, da comunicação digital, passando pelos avanços da tecnociência e da biotecnologia; 2. L'accélération du changement social - aceleração das mudanças sociais e culturais, significando formas efêmeras de associações, empregos, práticas, consumos, valores e estilos de vida; nas quais predominam a instabilidade e o esvaziamento de referências política, estética e ética e 3. L'accélération du rythme de vie - aceleração do ritmo de 
vida dos indivíduos, em que tanto o âmbito da esfera pública, quanto da esfera privada sofrem uma diluição das fronteiras. (ROSA, 2010, pp. 18-25. Tradução nossa)

Em termos psicossociais, duas pilastras erigem o super-homem contemporâneo: a performance e o narcisismo.

No que concerne aos ideais performáticos, o culto da performance de que nos fala Ehrenberg (2010), significa o enaltecimento da atividade e da ação em várias esferas da vida, em especial no desempenho do exercício do "empreendedorismo". O referido culto, fruto da ideologia neoliberal do capitalismo tardio, é pautado na exacerbação do individualismo e na cultura imagética. Destaca-se em seu interior três tipos de discursos: o esportivo, o do consumo e o empresarial, sendo que em todos eles a figura do empreendedor é o perfil ideal a ser alcançado, caracterizado por: desempenho exacerbadamente competitivo e obstinado, autorreferente, além de uma especial aptidão para assumir riscos e transpor todos os limites, sejam eles operacionais ou éticos. Importa ser bem sucedido e vencer a todo custo, visto que é predominantemente orientado pela racionalidade instrumental, cujos fins de eficácia justificam quaisquer meios.

Tal perfil observa-se em larga escala na publicidade contemporânea, o qual constitui-se em elemento de identificação idealizada, modelando assim a própria subjetividade dos homens. No caso dos produtos tecnológicos, o que almeja-se é a aquisição de um sentimento de potência auferido pelas novas tecnologias, não apenas com o intuito de crescer economicamente, mas de investir em realizações emocionais; já que os produtos também agregam atributos subjetivos tais como: reconhecimento, status, segurança, onipotência etc.

Estimula-se assim uma sociedade voltada para o ativismo de resultados imediatos: reagir, mais que refletir; comprovar, mais que analisar; apresentar dados, mais que questionar; mostrar resultados, mais que produzir sentidos. O saber-fazer é substituído pela performance; a formação pelo treinamento, a potência, pela onipotência e a ideia de "cuidado de si" pela "indústria das imagens de si". Esse perfil do superhomem coaduna-se com a descrição da "realidade pós-humana", baseada nas palavras de Hannah Arendt (1983, p.36 apud. NOVAES, 2009, p.13): 
É possível que nós, criaturas terrestres, que começamos a agir como habitantes do Universo, não sejamos mais capazes de compreender, ou seja, de pensar e exprimir as coisas que, no entanto, somos capazes de fazer. Neste caso, tudo se passaria como se nosso cérebro (...) não pudesse mais acompanhar o que fazemos, de modo que doravante teríamos realmente a necessidade de máquinas para pensar e para falar em nosso lugar.

Eis aí o grande prejuízo da realidade "pós-humana" que nos intima a analisar a demanda por super-homens na contemporaneidade. Guiados pela tecnologia e persuadidos de que por meio das últimas novidades do mercado serão capazes de "tudo poder", o indivíduo "pós-moderno" deixa de pensar e trabalhar na construção de sua própria subjetividade de forma autônoma. A heteronomia prevalece, na medida em que seus desejos são confundidos com os objetos de consumo tecnológicos, produzindo um esvanecimento do sentido de realidade. Assim, as fronteiras entre ficção e realidade se dissipam, enquanto o fascínio de se tornar cada vez mais "super" oblitera a capacidade de julgamento, denotando o caráter regressivo deste processo.

A ilusão de completude humana fornecida pelo objeto de consumo nos leva à outra pilastra, a partir da qual se erige o super-homem: a Cultura do Narcisismo (LASCH, 1983).

\section{A Onipotência narcísica contemporânea}

De acordo com diversos autores (LASCH, 1983; BAUDRILLARD, 1970; SENNETT, 1993 e COSTA, 1991) a tipologia de personalidade predominante na contemporaneidade é a narcisista. O narcisista contemporâneo é, fundamentalmente, egocentrado, particularista e hedonista; orientado pela busca de viver intensamente o presente, desprezando o passado e negligenciando o futuro. Particularmente fascinado pelo espetáculo das novas tecnologias informatizadas, está sempre em busca de "novas realizações", acreditando-se possuir a capacidade de dizer e fazer "quase tudo". É predominantemente manipulador, buscando exclusivamente a própria vantagem, em detrimento do outro, concebido apenas como instrumento de confirmação e admiração do próprio eu. (SEVERIANO, 2007) 
O termo narcisismo, tal como posto por Freud, designa um estado originário do homem anterior a constituição do ego como instância diferenciada do mundo, caracterizado por uma fusão eu + mundo. O processo de individualização, que se dá no decorrer da socialização do indivíduo, implicaria, necessariamente, no abandono da posição narcísica primária em direção às relações interpessoais e à realização de ideais culturais, fontes originárias de auto-estima.

No entanto, na chamada era "pós-moderna", cai o espírito universalizante e utópico das décadas anteriores, prevalecendo um vazio político, social, cultural e afetivo. Isto contribuiu para a exacerbação de novas fontes constituintes de identidade, não mais pautadas nos ideais de um projeto emancipatório e coletivo, mas em saídas regressivas que apelam para processos primários inconscientes e mecanismos psíquicos de idealização. A "idealização", segundo Freud, é um mecanismo psíquico pelo qual as qualidades e o valor do objeto são levados à perfeição sem nenhuma consideração pela realidade, promovendo assim uma falsa conciliação entre sujeito e objeto.

As "saídas regressivas" se expressam, contemporaneamente, nas mais diversas formas de "reencantamento" e identificação idealizada com o objeto de consumo. Neste sentido, podemos dizer que os antigos ideais coletivos foram substituídos por micro ideais, agora de grande potência porque referidos a um suposto superpoder do indivíduo - o "super-homem".

No caso do objeto tecnológico, este, toma a forma de "objeto idealizado", portador de uma imaginária onipotência narcísica, capaz de uma espécie de autoobturação de toda falta humana. Assim, diante de um mundo que perdeu suas "memórias coletivas" e suas "utopias", a necessidade de ilusões intensifica-se mais ainda, passando a volição individual a tornar-se todo-poderosa, aos moldes da onipotência narcísica.

\section{Controle e reconhecimento social - "por um pedaço de fita..."}

Alguém disse certa vez que o homem jamais venderia sua vida, mas a entrega de graça por um pedaço de fita colorida ${ }^{3}$. Uma clara alusão aos militares, que por afeição

\footnotetext{
${ }^{3}$ Da obra "O monge e o executivo", de James C. Hunter, 2004.
} 
aos ideais de Nação, entregam suas vidas para servir ao país em guerra em troca de patentes, honrarias e prestígio social. Talvez hoje possamos transferir a ideia para a questão do tempo: se perguntarmos a alguém abertamente "por quanto você me vende o seu tempo livre, de lazer com os amigos ou gozo da família?" dificilmente teríamos uma resposta explicitamente afirmativa.

Mas o que ocorre hoje senão a doação/venda implícita desse tempo? Troca-se o tempo com a família por horas extras de trabalho a fim de acumular mais capital. Trocase o tempo com os amigos por "atualizações" do Facebook a fim de parecer mais atrativos. Será que seguimos fascinados pelo "pedaço de fita"?

Em primeiro lugar, acreditamos que permanece hoje, de maneira sutil, a ideia do "pedaço de fita", que nos remete ao prestígio ou reconhecimento social. Ser considerado empreendedor é possivelmente um dos maiores motivos de prestígio social da contemporaneidade. Observe como são elogiadas as pessoas que possuem mais de um emprego e ainda estudam e fazem inúmeros cursos - a formação permanente; essas pessoas são vistas como "versáteis", "winners". Estar disponível via celular, e-mail ou redes sociais por 24 horas é uma demanda frequente de diversas empresas, enquanto muitas pessoas se sentem prestigiadas, justamente, por serem solicitadas constantemente, mesmo em seu tempo de não trabalho. Deste modo, a tecnologia sempre se apresenta como uma ferramenta de reconhecimento; dificilmente cogita-se que ela seja cúmplice da venda ou mesmo do sequestro do tempo livre. Uma nova forma de controle social.

A noção de flexitempo descrita por Sennett (2010) explicita este regime. O fato de em várias empresas os turnos fixos estarem sendo substituídos por turnos "flexíveis" ou até mesmo pelo "trabalhar em casa", não significa liberação do tempo de trabalho. Isto porque, apesar de tal organização ter uma aparência de liberação, subvertendo rotinas e propiciando opções de escolhas, Sennett denuncia esta forma de organização como um engodo:

Um trabalhador em flexitempo controla o local do trabalho, mas não adquire maior controle sobre o processo de trabalho em si [...] A supervisão do trabalho muitas vezes é na verdade maior para os ausentes do escritório que para os presentes [...] Os trabalhadores assim, trocam uma forma de submissão ao poder - cara a cara - por outra, eletrônica [...] A "lógica métrica" do tempo de Daniel Bell passou do relógio de ponto para a tela do 
computador. O trabalho é fisicamente descentralizado, o poder sobre o trabalhador mais direto. (SENNETT, 2010, p. 68-67)

Assim, a máxima do capitalismo industrial de que "Tempo é dinheiro", hoje se expande para todas as esferas da vida social, auxiliada pela portabilidade tecnológica, dissolvendo inclusive as fronteiras entre tempo livre e tempo de trabalho. Logo, não se trata apenas de ser o funcionário mais bem qualificado, mas o mais "disponível, "o primeiro a chegar".

É uma tarefa árdua para muitos entender que "chegar" a algum lugar pode ser mais importante do que alcançá-lo primeiro. Aqui o que conta é a performance, não o fim último da chegada. Na verdade, parece que se está sempre de "partida", nesta Modernidade Líquida (BAUMAN, 2001), onde a profusão de múltiplas escolhas torna qualquer opção insuficiente. Mundo em que "poucas coisas são predeterminadas, e menos ainda irrevogáveis. Poucas derrotas são definitivas, pouquíssimos contratempos, irreversíveis; mas nenhuma vitória é tampouco final” (BAUMAN, 2001, p.74). Ou seja, nada é "suficiente", não há um ponto final! É preciso produzir mais, estudar mais, viajar mais, comprar mais, fazer mais... Como o próprio Rosa (2010) afirma, é preciso correr para, pelo menos, permanecer no mesmo lugar, como em uma esteira rolante.

O Culto da Performance, de que nos fala Ehrenberg (2010) também trata da expansão da competitividade, própria do esporte, para toda a vida dos indivíduos, tornando-se um "sistema de conduta em si" (p.18). Mais do que isso, a busca por um maior desempenho denuncia uma compensação das desigualdades sociais, uma falsa conciliação que mistifica o caráter político da conquista por benesses sociais. Assim:

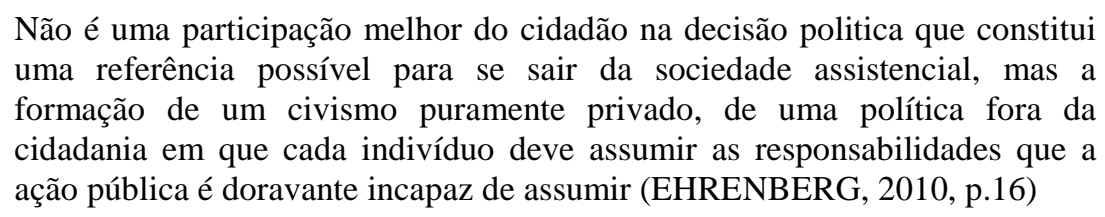

Logo, soa plausível que o homem por meio de seu desempenho e aptidões seja dono de si mesmo, viva correndo para o sucesso e, enfim, carregue o fardo de encontrar e construir a sua felicidade com as próprias mãos.

Discursos que incitam ao empreendedorismo, à pró-atividade e ao investimento pessoal, do tipo "Você pode!", "Seja empreendedor" ou "O sucesso só depende de 
você" parecem amigáveis conselhos, no entanto carregam consigo ideais próprios à lógica produtivista no interior da esfera privada, ao mesmo tempo em que enfraquecem a esfera pública a partir de mandatos dessolidarizantes e moralistas, que só engolfam o homem em uma multiplicidade de obrigações cotidianas inatingíveis, fazendo-o sentirse sempre atrasado e insuficiente.

Ora, um dos maiores "pecados" da sociedade contemporânea diz respeito a ser um "estulto", um fraco de vontade, como descreve Jurandir Freire Costa (2005, p.195):

Estultícia é a inépcia, a incompetência para exercer a vontade no domínio do corpo e da mente, segundo os preceitos da qualidade de vida. O louco de outrora ameaçava a cultura por ser um contra-exemplo vivo da ideia do homem como ser racional. (...) O estulto ameaça pelo mau exemplo da fraqueza de vontade.

$\mathrm{Na}$ contramão do empreendedorismo e do desempenho, ser estulto implica, portanto, em ser visto como um loser, um perdedor. Mas, aos super-homens não lhes é dado o direito de demonstrar fraqueza, própria da condição humana. É necessário ser um "pós-humano" para lidar com as demandas vigentes. Neste sentido, a busca para ser reconhecido como um winner configura-se como um dos mais relevantes fatores da aceleração do viver, posto que incentiva a participação e contribuição dos indivíduos em troca de reconhecimento e engajamento no todo social. Pouco tempo resta para o ócio criativo e a reflexão: "Querer desenvolver diferentes talentos, recusar a especialização, será visto como falta de seriedade, como próprio do temperamento preguiçoso, porque, para fazer funcionar de maneira ótima o sistema capitalista, cada um deve ser monomaníaco" (GROS, 2012, p.259).

Ora, dificilmente alguém abdicaria de seu tempo se não acreditasse que "vale a pena" e que é "possível chegar lá". Parece que em algum momento do futuro toda a correria valerá a pena, mas até lá é preciso continuar correndo. Essa é a "lógica do desvio", termo utilizado para denunciar como os indivíduos contemporâneos perderam o foco de suas conquistas. Tal lógica diz respeito à ideia de "recuar para melhor saltar", algo simples, mas que pode gerar um engodo perigoso: "Aquele que é animado pelo espírito do desvio pode deixar-se apanhar em sua armadilha perdendo de vista que o desvio é apenas um desvio" (DUPUY, 2012, p.298). Isto é, os indivíduos performáticos, em suas metas por felicidade e para melhor alcança-la "recuaram" para o âmbito do trabalho excessivo, dos intensos fluxos nas redes sociais, das constantes viagens de 
curta duração, findando por enredar-se em ritmos de vida tão acelerados, que torna inviável a meta da felicidade. Ou seja, perderam-se nesse recuo: esqueceram-se do "salto", esqueceram-se do porquê de suas performances e para onde elas deveriam levar.

Perdemo-nos, assim, numa infinita sucessão de meios, nos pequenos adiamentos em que a finalidade almejada se perde e nossos ideais passam a ser modelados por outros: seja pela lógica concorrencial da racionalidade técnica, seja pelos ditames do consumo e da mídia. Ou seja, a finalidade do prazer, da chegada ou dos encontros se dissolve no fluxo acelerado das demandas do dia a dia, resultando em subordinação explícita ou implícita ao grande pregão do tempo ditado pela lógica do capital. O projeto utópico do futuro parece já ter sido comprado pelo capitalismo.

Desse modo, a busca por reconhecimento social finda por disciplinar o homem em vez de libertá-lo: "O princípio da disciplina é impor à vida, justamente, essas regularidades mecânicas, essa ordem fria e implacável. A função da disciplina, portanto, é fazer o corpo vivo se conectar com a máquina, é transformar o corpo vivo em corpomáquina" (GROS, 2012, p.260).

A pressão social que se alastra, por vezes disfarçada de interatividade, é uma forma sutil de disciplinamento dos indivíduos, na medida em que torna cada um o vigilante atento de muitos. Procede-se assim a uma auto-regulação sem precedentes, viabilizada pelas demandas midiáticas e pela extrema visibilidade propiciada pela informática, administrada por uma mentalidade de manager que a tudo quer controlar.

\section{Superprodutos e Indústria cultural publicitária - o tempo-mercadoria.}

A partir da concepção de consumo em seu "valor signo" (BAUDRILLARD, 1976) e da Publicidade como uma instância que não apenas reflete a subjetividade de seus consumidores, mas torna-se ela própria produtora de subjetividades (SEVERIANO, 2010, p.3), analisaremos duas campanhas publicitárias, cuja argumentação aufere ao tempo um valor de mercadoria, com fortes apelos à aceleração e aos poderes ilimitados. 
CONHEÇA UMA

SUPEROFERTA DA OI.

SMARTPHONES QUE PODEM

ATÉ SAIR DE GRAÇA.

OI FAMÍLIA SMARTPHONE COM TUDO ILIMITADO

LIGAÇÕES LOCAIS PRA OI E OI FIXO

INTERNET PRA CELULAR + OI WIFI.

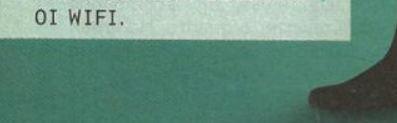

A OI COMPLETA VOCÊ.

प. 9 वा

Pra mais informaçōes, vá a uma loja Oi ou acesse oi.com.brimonteseuplano

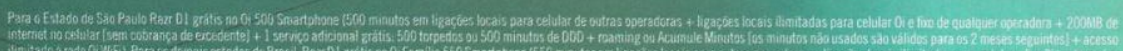

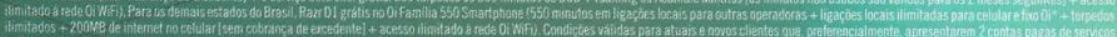

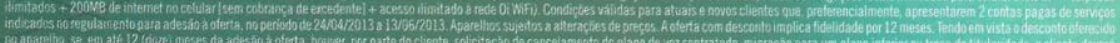

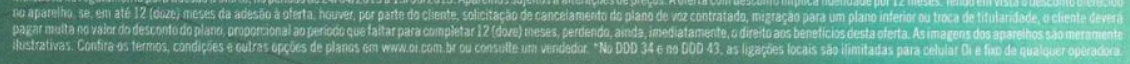


Figura 1 - Campanha Família Fantástica da Oi

Fonte: Revista Veja, edição 2320, ano 46, nº 19, p.44, mai., 2013

A Família Fantástica da $O i$, operadora de telefonia, torna-se "imbatível” após o chefe da família decidir dar a todos os membros smarthphones com planos para "falar ilimitado". Os personagens, membros da família, estão todos devidamente vestidos como super-heróis, em clara alusão aos superpoderes promovidos por objetos tecnológicos próprios dos super-homens. Todos os problemas da família parecem se resolver de forma miraculosa, pois seus poderes se concretizam ao adquirir os produtos e pacotes anunciados. Aqui, na figura do herói está implícita a do empreendedor, pois "é na figura do empreendedor e no desenvolvimento, ao mesmo tempo recente e rápido dos modos de ação empreendedores, que o heroísmo encontra sua forma dominante" (EHRENBERG, 2010, p.13).

Assim, om a aquisição do serviço, a família se encontra cercada de facilidades que possibilitarão interação "ilimitada" por 24 horas e potência para a realização das mais diversas atividades. Suas novas próteses lhes conferem uma nova maneira de habitar o mundo, "com nova ambiência, código próprio e sugestões de conduta", como já nos afirmara Sodré (2006, p.21). Nesse caso, o fortalecimento dos laços familiares, amalgamado pelos poderes da tecnologia, figura como uma outra dádiva propiciada pelo serviço, formando assim uma super "família-modelo".

A assinatura dessa campanha ao afirmar que "A Oi completa você" também faz um apelo ao ideal de completude e onipotência narcísica, atrelada aos objetos tecnológicos de consumo. Os Narcisos vislumbram aqui um desejo de retorno a ideais muito particularistas (a família), como forma de investir em suas capacidades e realizações, tornando-se heróis de si mesmos. A ambiência deste mundo fantástico, assim como os poderes auferidos, são da esfera do imaginário, mas se apresentam como possíveis, numa diluição das fronteiras entre realidade e ficção.

Em termos frankfurtianos, a adesão aos apelos de completude pela via do objeto implica numa falsa conciliação entre sujeito e objeto, indivíduo e sociedade, mediados pela indústria cultural. Aqui o mundo torna-se dominado, pacificado e a família coesa em seus poderes. Ocorre então a "miraculosa integração" referida por 


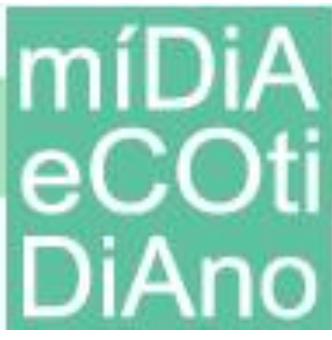

(BAUDRILLARD, 1993): "Este objeto você não o comprou, você emitiu o desejo de possuí-lo e todos os engenheiros, técnicos etc. o gratificaram com ele” (p.184).

No entanto, a inversão entre a lógica do desejo e a lógica do mercado aqui opera. Ou seja, apesar dos apelos serem da ordem do desejo e da emoção, o fim último é de ordem econômica. Será a família que, a partir de então, estará sob a dependência da tecnologia; posto que ela só se concretiza como "super" ao possuir os smarthphones. Isto é, os atributos subjetivos imputados às mercadorias passam a ser integrantes do homem, ocultando sua própria subjetividade, fenômeno próprio do duplo-fetichismo. (SEVERIANO, 2007)

Outra campanha, também de uma operadora de telefonia, anuncia uma nova tecnologia: a 4GMAX da Claro. Por meio dela será possível, aos que possuem aparelhos compatíveis, uma velocidade maior para aplicativos, programas, gadgets e web. Para divulgar essa nova tecnologia, a Claro apostou em uma série de vídeos e imagens que argumentassem em torno do reconhecimento sócio-afetivo: da promoção de vínculos interpessoais e sentimentos de pertença, amor e amizade.

Figura 2 - Banner de lançamento da tecnologia 4GMAX

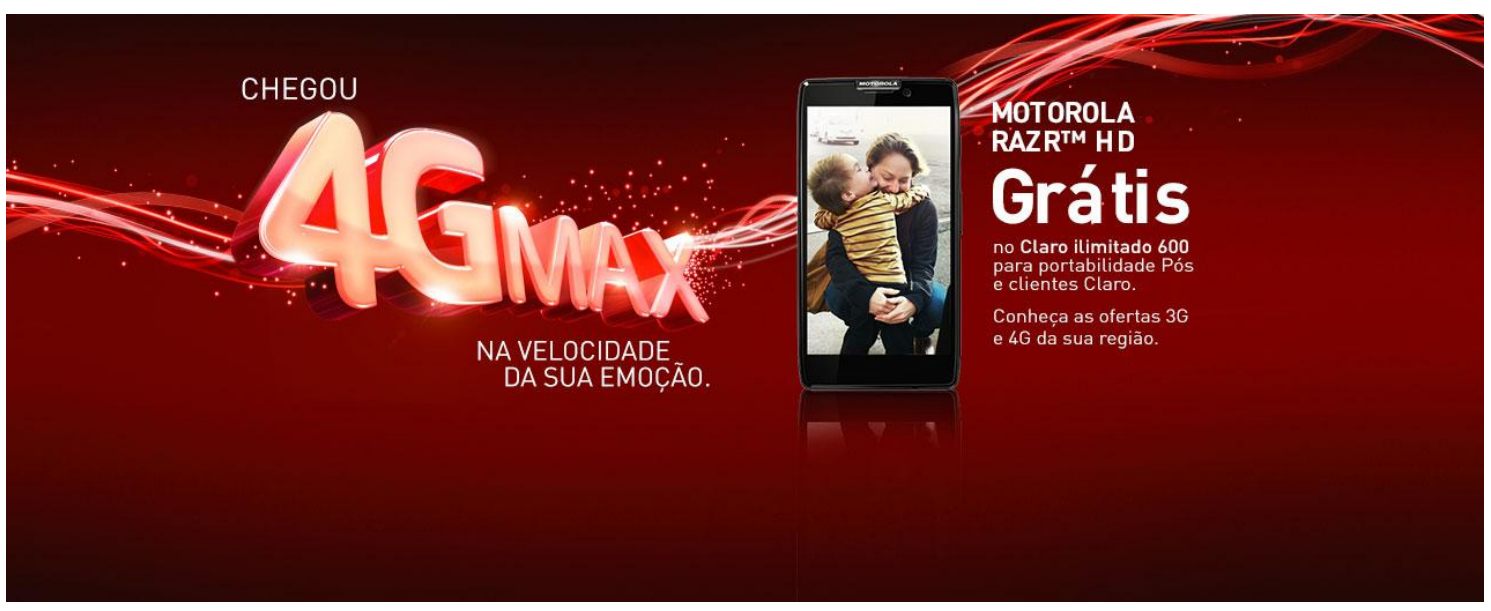

Fonte: Site da Claro. Disponível em: http://www.claro.com.br/internet/4g-max/regiao/ddd85/CE/tv-2/. Acesso em 06 de março de 2013.

Aqui duas instâncias são arbitrariamente unidas em sua assinatura: a velocidade e a emoção. O primeiro passo do seu filho, o ingresso dele na faculdade ou qualquer outro momento único necessita agora de um registro ou compartilhamento via 
tecnologia para ser verídico. Em um dos vídeos promocionais ${ }^{4}$ a locução off diz: “ $A$ emoção de ver o seu filho se preparando para o futuro não pode esperar, por isso a Claro está trazendo a internet móvel mais rápida do mundo: 4GMAX. Agora você vai ver e viver os momentos na hora em que acontecem, onde quer que você esteja".

A pressão social que argumenta que os momentos passam e você precisa ser veloz o suficiente para registrá-los é própria da força motriz concorrencial nas diversas esferas da vida, no capitalismo financeiro (Ehrenberg, 2010). Solicita-se, no caso, que o homem acelere sua vida em função de conseguir boas imagens que resultarão em elogios e aplausos, através do "compartilhamento" on line de momentos de "grande emoção". Com a internet "mais rápida do mundo" será possível a dádiva de não perder aquilo que "não pode esperar". Pois, sem esse registro, parece que a emoção não existe.

No lugar de um tempo de "duração", da experiência do tempo distendido, (KEHL, 2009) necessário à reflexão e à integração da emoção à própria experiência temos um tempo premido pelo "aqui e agora", fragmentado a cada instante. Esta é uma característica própria do imediatismo da sociedade contemporânea e também um fator determinante das performances. A tentativa de lidar com a finitude da vida configura-se como uma força motriz da aceleração social. (ROSA, 2010). Assim, agimos como se à vida não se pudesse dar o tempo da espera, posto que um dia ela findará. Viver intensamente, viver tudo ao mesmo tempo, torna-se o imperativo. Como se quiséssemos viver muitas vidas em uma só. Os momentos, de fato, passam ante os nossos olhos e são registrados em flashs, mas não perpassam nosso viver. Não adquirimos "experiência", no sentido definido por Bondía (2002) como: “o que nos passa, o que nos acontece, o que nos toca" (p.21, grifos nossos). Mas, as imagens, pessoas e fenômenos simplesmente "se passam", transcorrem ante nossa visão, desfilam enquanto acontecimentos exteriores. Constituem-se em meros "experimentos" que não nos toca, visto que não há tempo suficiente para se transformar na "minha experiência".

O acontecimento nos é dado na forma de choque, do estímulo, da sensação pura, na forma da vivência instantânea, pontual e fragmentada. A velocidade com que nos são dados os acontecimentos e a obsessão pela novidade, pelo novo, que caracteriza o mundo moderno, impedem a conexão significativa entre acontecimentos. (BONDÍA, 2002, p.23)

\footnotetext{
${ }^{4}$ Disponível em http://www.youtube.com/watch?v=Yb5YSU0zDTM. Acesso em 29 de Outubro de 2013.
} 
Com efeito, vivemos na "Sociedade do Espetáculo", há décadas conceituada por Debord (1997), na qual as relações sociais e pessoais são mediadas por imagens. Ou, como afirma Maria Rita Kehl (2005) vivemos em um mundo "muito além do espetáculo", um mundo em que "a circulação veloz e abrangente das imagens/mercadorias nos faz ver que o espetáculo segue a todo vapor [...], cuja forma predominante e mais eficiente em matéria de produção de subjetividade é a imagem da marca publicitária" (p.237). Deste modo, ainda mais do que antes, hoje é preciso se relacionar por imagens, constante e rapidamente, pois "a cultura do excesso ameaça a todos de rápida obsolescência" (KEHL, 2005, p.244).

\section{Reflexões finais}

Em meio ao paradoxo da vertiginosa expansão tecnológica informatizada e a crescente "escassez de tempo" vigente, o homem contemporâneo persegue o ritmo de suas próteses maquínicas em busca de "tudo-fazer", em tempo recorde. No entanto, apesar do avanço técnico, ontem, como hoje, o sistema permanece irracional no que concerne ao bem estar humano.

A irracionalidade objetiva do sistema apontada por Adorno e Horkheimer (1991) na Dialética do Esclarecimento segue sua escalada nas sociedades do capitalismo financeiro. Ou seja, a discrepância entre "progresso tecnológico" e "progresso humanitário" (Marcuse, 1982), em que ocorre uma distribuição irracional dos bens objetivos e subjetivos que a civilização já conquistou resulta hoje em uma subordinação cada vez maior do homem ao aparato produtivo, tecnológico e de consumo, concebido como um fim em si mesmo. "O medo de que o homem seja escravizado por suas máquinas deu lugar a uma esperança de que o homem se transforme em algo parecido a uma máquina" (LASCH, 1983, p. 48). Um superhomem.

Os apelos à onipotência e ao reconhecimento sócio-afetivo são veiculados insistentemente pela Indústria Cultural publicitária. À agregação de superpoderes aos objetos tecnológicos veiculados, mais exigências performáticas são demandadas e maior é a sensação de "escassez de tempo"; assim como menor é a capacidade produção de sentido para as próprias experiências. A potencialidade de crítica dá lugar à 
confiabilidade no potencial tecnológico e à fetichização no consumo. Sucumbimos assim num ciclo de idealização-consumo-aceleração. E, mais como Narcisos do que como Heróis de causas coletivas, prosseguimos exaustivamente na tentativa de sermos "super-homens", tentando salvar a nós mesmos.

Notadamente, seja para ser reconhecido como empreendedor, seja para investir nas suas relações familiares ou sociais, expondo suas "pseudoexperiências" diárias em busca de aplausos, os Narcisos performáticos da contemporaneidade perseguem ainda $o$ almejado "pedaço de fita".

\section{Referências}

ADORNO, T. A indústria cultural. In: COHN, G. (Org.). Comunicação e indústria cultural. 4. ed. São Paulo: Nacional, 1978.

Paulo:Ática, 1986.

Indústria cultural. In: COHN, Gabriel. Theodor Adorno: sociologia. São

ADORNO, Theodor W..; HORKHEIMER, Max . Dialética do esclarecimento: Fragmentos filosóficos. Tradução de Guido Antônio de Almeida. 3.ed. Rio de Janeiro: Jorge Zahar Editor, 1991. 254p.

ARENDT, Hannah. Condition de l'homme modern, 1983. In: NOVAES, Adauto (Org). A condição humana: as aventuras do homem em tempos de mutações. Rio de Janeiro: Agir; São Paulo: Edições SESCSP, 2009.

BARTHES, Roland. Mitologias. Tradução de Rita Buongermino e Pedro de Souza. 9.ed. Rio de Janeiro. Bertrand Brasil, 1993.

BAUDRILLARD, Jean. A sociedade de consumo. Tradução de Artur Morão. São Paulo: Livraria Martins Fontes, 1970.

La génesis ideológica de las necesidades. Tradução de Joaquin Jordá. Barcelona: Editorial Anagrama, 1976.63p.

Significação da publicidade. In: LIMA(Org.). Teoria da cultura de massa. 2.ed. Rio de Janeiro:Paz e Terra, 1978. p.148-149.

O sistema dos objetos. Tradução Zulmira Ribeiro Tavares; Revisão por Geraldo Gerson de Souza e Mary Amazonas Leite de Barros. São Paulo: Perspectiva, 1993. 231p. (Debates, 70)

BAUMAN, Z. Modernidade líquida. Rio de Janeiro: Jorge Zahar, 2001.

BONDÍA, Jorge Larrosa. Notas sobre a experiência e o saber da experiência. Tradução de João Wanderley Geraldi. Revista Brasileira de Educação. Rio de Janeiro, n.19, jan./abr., p.20-28, 2002. 
COSTA, Jurandir Freire. Violência e psicanálise. 2.ed. Rio de Janeiro: Edições Graal,1986. 189p. (Biblioteca de Psicanálise e Sociedade 3).

psicanálise. São Paulo: Brasiliense, 1991.

"Narcisismo em tempos sombrios". In: Tempo do desejo: sociologia e $O$ Vestígio e a Aura: corpo e consumismo na moral do espetáculo.

Rio de Janeiro: Garamond, 2005.

DEBORD, GUY. A sociedade do espetáculo. Rio de Janeiro: Contraponto, 1997.

DUPUY, Jean-Pierre. O tempo que nos resta. In: NOVAES, Adauto (org). Mutações: elogio à preguiça. São Paulo: Edições SESCSP, 2012. p. 295-316.

EHRENBERG, Alain. $O$ culto da performance: da aventura empreendedora à depressão nervosa. São Paulo: Ideias e Letras, 2010.

FREUD, Sigmund. Sobre o narcisismo: uma introdução. Tradução de Jayme Salomão e Themira de Oliveira Brito; revisão Técnica de Darcy de Mendonça Uchôa Rio de Janeiro: Imago, 1976. (Obras Completas de Sigmund Freud, Vol. 14).

GIANNETTI, Eduardo. Felicidade. São Paulo: Companhia das Letras, 2002.

GROS, Frédéric. Preguiça e Capitalismo. In: NOVAES, Adauto (org). Mutações: elogio à preguiça. São Paulo: Edições SESCSP, 2012. p. 253-265.

KEHL, M. R.; BUCCI, E. Visibilidade e Espetáculo. In: Videologias: ensaios sobre televisão. São Paulo: Boitempo, 2004.

Muito além do espetáculo. In: NOVAES, Adauto (Org.). Muito além do espetáculo. São Paulo: Editora Senac São Paulo, 2005, p.234-253.

Os tempos do outro. Em O tempo e o cão: a atualidade das depressões. São Paulo: Boitempo, 2009.

LASCH, Christopher. A cultura do narcisismo: a vida americana numa era de esperanças em declínio. Tradução de Ernani Pavareli; direção de Jayme Salomão. Rio de Janeiro: Imago, 1983. 320p. (Série Logoteca).

MARCUSE, H. Introdução. In: A ideologia da sociedade industrial: o homem unidimensional. Rio de Janeiro: Jorge Zahar, 1982.

MARX, Karl. Fetichismo e Reificação. In: IANNI, O. (Org.). Sociologia. São Paulo: Atica, 1984.

NOVAES, Adauto. Entre dois mundos. In: NOVAES, Adauto (org). A condição humana: as aventuras do homem em tempos de mutações. Rio de Janeiro: Agir; São Paulo: Edições SESCSP, 2009. p. 9-35.

ROSA, Hartmut. Aliénation et accélération: vers une théorie critique de la modernité tardive. Paris: Découvert, 2010

SENNETT, Richard. O Declínio do homem público: as tiranias da intimidade. Tradução de Lygia Araújo Watanabe. 3.reimp. São Paulo: Companhia das Letras, 1993. 447p. 
A Corrosão do Caráter: consequências pessoais do trabalho no novo capitalismo. Rio de Janeiro: Record, 2010.

SEVERIANO, Maria de Fátima Vieira. Narcisismo e Publicidade: uma análise psicossocial dos ideais de consumo na contemporaneidade. São Paulo: Annablume, 2007.

SEVERIANO, Maria de Fatima V. Lógica do Mercado e Lógica do Desejo: reflexões críticas sobre a sociedade de consumo contemporânea a partir da Escola de Frankfurt. In: Soares J. C. (Org.). Escola de Frankfurt: inquietudes da razão e da emoção. Rio de Janeiro: EdUERJ, 2010.

SEVERIANO, Maria de Fátima V.; BENEVIDES, Pablo Severiano. "Tempo livre" consumado: indústria cultural, consumo e novas tecnologias no contexto do novo espirito do capitalismo. In: EWALD, Ariane P. et al. (Orgs.). Tempo e subjetividades: perspectivas plurais. Rio de Janeiro: 7letras: Pequeno Gesto, 2013, p.37-59.

SODRÉ, Muniz. Eticidade, Campo Comunicacional e Midiatização. In: Dênis de Moraes (Org.). Sociedade midiatizada. Rio de Janeiro: Mauad, 2006. 